\title{
Covid-19: testing times
}

\author{
Rapid near patient testing for both current and past infections is urgently required
}

\author{
Nick J Beeching consultant, Tom E Fletcher senior lecturer, Mike B J Beadsworth clinical director
}

Tropical and Infectious Disease Unit, Royal Liverpool University Hospital and Liverpool School of Tropical Medicine, Liverpool, UK

"Test, test, test" is the key to controlling the spread of

SARS-CoV-2 and its clinical manifestation, covid-19, according to the World Health Organisation. ${ }^{1}$ However, three months after notification of the novel coronavirus infection in China, there is inadequate access to appropriate diagnostic tests globally and confusion among healthcare professionals and the public about prioritisation of testing and interpretation of results.

The virus is spread by the respiratory route, primarily by droplets and contact with contaminated surfaces and fomites, and by aerosol formation during invasive respiratory procedures. Virus is also found in urine, faeces, and saliva. ${ }^{2-5}$ Asymptomatic shedding seems to be common, especially in children, and can spread infection. ${ }^{67}$

The incubation period from infection to first symptom is typically 5 to 7 days, with a range of 4-14 days. Diagnosis of current infection relies on tests to detect virus in various body fluids. Antibody tests on blood are used to confirm past infection and presumed immunity to repeat infection, although duration and effectiveness of such protection are not yet known.

\section{Swab tests}

Respiratory shedding of virus peaks at the end of the first week after infection, just before and as symptoms are developing. It may be intermittent, so a single negative swab result can be misleading and tests may need to be repeated. ${ }^{1-3}$ Swabs must be taken correctly and transported in viral transport medium. ${ }^{8}$

Nasopharyngeal swabs are more sensitive than oropharyngeal swabs and are best taken when symptoms first emerge. ${ }^{3-589}$ Swabs from both sites are often combined to increase sensitivity. Deeper respiratory secretions such as sputum and bronchoalveolar fluid contain more virus, and yields increase over 2-3 weeks in more severe cases. ${ }^{3-510}$ Faecal virus shedding can persist after resolution of diarrhoea.

The gold standard test for diagnosis is detection of viral RNA by molecular methods, typically a reverse transcription polymerase chain reaction (RT-PCR). Test protocols require substantial equipment, reagents, and expertise and are often carried out in central or regional laboratories, especially in resource poor settings. Delays in transporting samples to the laboratory and returning results to the originator mean that overall test turnaround often exceeds 48 hours. Decentralisation of laboratories helps reduce these delays, but validated rapid near-patient tests are urgently needed to provide more timely information for both diagnosis and public health interventions. ${ }^{11}$

Novel systems are being assessed for faster detection of key viral sequences ${ }^{5112}$ and a variety of point-of-care antigen detection devices have been developed, but their performance varies widely. Some antigen detection devices have poor sensitivity, meaning that infections are missed and infectious individuals are not managed appropriately. ${ }^{11}$

\section{Antibody tests}

Antibody tests are primarily used to determine if a person has already had covid-19. Specific IgM and IgG antibodies should start to become detectable after 4-5 days, with positive IgM antibodies in $70 \%$ of symptomatic patients by days $8-14$ and $90 \%$ of total antibody tests positive by days $11-24$. IgG reactivity is thought to reach $>98 \%$ after several more weeks, but duration of this antibody response is not yet known. ${ }^{3} 1314$

Antibodies can be detected by conventional ELISA tests or with near-patient lateral flow devices, similar to those used for pregnancy testing. These can deliver results in less than 20 minutes from a few drops of blood obtained by finger prick. They usually combine tests for $\operatorname{IgM}$ and $\operatorname{IgG}$ and may not become positive until the second week of infection and sensitivity may be lower after asymptomatic infection. ${ }^{14} 15$ Antibody detection tests may also be limited by poor specificity, so people are wrongly identified as having been infected and have a false sense of security. ${ }^{14}$

Who should be tested? In countries such as Singapore and South Korea, aggressive programmes of testing, contact tracing, and isolation have contributed to early control of infection. As the epidemic progresses, the focus is on symptomatic patients and key workers and their families. Testing symptomatic patients for current infection when they attend healthcare facilities can inform contact tracing and infection prevention and control, particularly in the triage of patients to appropriate wards in hospital. Key workers, especially those in healthcare, may be self-isolating for long periods if a household member has symptoms. Exclusion of infection in the household enables staff to return to work, as would proof of staff immunity. 


\section{Game changer}

Wide availability of testing for antibodies would be a game changer. Many healthcare staff are likely to have already been infected in the community or at work. Identification of resolved past infection could allow these people to return to work, on the assumption that past infection confers some level of immunity. Contacts of people who are currently infected could have antibody tests to find out whether they were still at risk.

As antibody testing becomes more widely available throughout the community, a clearer picture should emerge of the proportion of infections that are asymptomatic and the true morbidity of covid-19. ${ }^{16-18}$

In summary, interpretation of tests depends on the biological site and timing of samples, and recognition of both intermittent viral shedding and variation in the sensitivity and specificity of different test systems. New tests must be properly validated before use in any given setting, as "an unreliable test is worse than no test." ${ }^{19}$ However, tests cannot be interpreted if they are not available - and that is the major challenge currently facing many countries, including the UK.

Competing interests: The BMJ has judged that there are no disqualifying financial ties to commercial companies. The authors declare no other interests. The BMJ policy on financial interests is here: https://www.bmj.com/sites/default/files/ attachments/resources/2016/03/16-current-bmj-education-coi-form.pdf."

Provenance and peer review: Commissioned; not externally peer reviewed.

1 World Health Organization. Laboratory testing strategy recommendations for COVID-19. 22 Mar 2020. https://apps.who.int/iris/bitstream/handle/10665/331509/WHO-COVID-19lab_testing-2020.1-eng.pdf

2 Huang C, Wang Y, Li X, etal. Clinical features of patients infected with 2019 novel coronavirus in Wuhan, China. Lancet 2020;395:497-506 10.1016/S0140-6736(20)30183-5 31986264

3 Zhang W, Du RH, Li B, etal . Molecular and serological investigation of 2019-nCoV infected patients: implication of multiple shedding routes. Emerg Microbes Infect 2020;9:386-9. 10.1080/22221751.2020.172907132065057
4 Wang W, Xu Y, Gao R, etal . Detection of SARS-CoV-2 in different types of clinical specimens. JAMA 2020. 10.1001/jama.2020.3786 32159775

5 Loeffelholz MJ, Tang Y-W. Laboratory diagnosis of emerging human coronavirus infections-the state of the art. Emerg Microbes Infect 2020;9:747-56. 10.1080/22221751.2020.1745095 32196430

6 Wang C, Liu L, Pan A, et al. Evolving epidemiology and impact of non-pharmaceutical interventions on the outbreak of coronavirus disease 2019 in Wuhan, China.MedRxiv2020.03.03.20030593. [Preprint]. doi10.1101/2020.03.03.20030593.

7 Mizumoto K, Kagaya K, Zarebski A, Chowell G. Estimating the asymptomatic proportion of coronavirus disease 2019 (COVID-19) cases on board the Diamond Princess cruise ship, Yokohama, Japan, 2020. Euro Surveill 2020;25:2000180. . 10.2807/1560-7917.ES.2020.25.10.2000180 32183930

8 Carver $\mathrm{C}$, Jones N. Comparative accuracy of oropharyngeal and nasopharyngeal swabs for diagnosis of COVID-19. Oxford COVID-19 evidence service team centre for evidence based medicine. 2020. https://www.cebm.net/covid-19/comparative-accuracy-oforopharyngeal-and-nasopharyngeal-swabs-for-diagnosis-of-covid-19/

9 Zou L, Ruan F, Huang M, etal . SARS-CoV-2 viral load in upper respiratory specimens of infected patients. N Engl J Med 2020;382:1177-9. . 10.1056/NEJMc2001737 3207444

10 Yang $\mathrm{Y}$, Yang M, Shen C, et al. Evaluating the accuracy of different respiratory specimen in the laboratory diagnosis and monitoring the viral shedding of 2019-nCoV infections. MedRxiv 2020.02.11.20021493. [Preprint] 0.1101/2020.02.11.20021493

11 Sheridan C. Fast, portable tests come online to curb coronavirus pandemic. Nat Biotechnol 2020. [Epub ahead of print] 10.1038/d41587-020-00010-2 32203294

12 Moore SC, Penrice-Randal R, Alruwaili M, et al. Amplicon based MinION sequencing of SARS-CoV-2 and metagenomic characterisation of nasopharyngeal swabs from patients with COVID-19. MedRxiv 2020.03.05.20032011. [Preprint] 10.1101/2020.03.05.20032011.

13 Zhao J, Yuan Q, Wang H, etal . Antibody responses to SARS-CoV-2 in patients of novel coronavirus disease 2019. Clin Infect Dis 2020:ciaa344; [Epub ahead of print]. 10.1093/cid/ciaa344 32221519

14 Li Z, Yi Y, Luo X, etal . Development and clinical application of a rapid IgM-IgG combined antibody test for SARS-CoV-2 infection diagnosis. J Med Virol 2020. [Epub ahead of print]. .10.1002/imv.25727 32104917

15 Okba NMA, Müller MA, Li W, et al. SARS-CoV-2 specific antibody responses in COVID-19 patients. medRxiv 2020.03.18.20038059. [Preprint.] 2020. https://doi.org/10.1101/2020.03.18.20038059

16 European Centre for Disease Control. Novel coronavirus disease 2019 (COVID-19) pandemic: increased transmission in the EU/EEA and the UK-sixth update. $12 \mathrm{Mar}$ 2020.https://www.ecdc.europa.eu/sites/default/files/documents/RRA-sixth-update-Outbreakof-novel-coronavirus-disease-2019-COVID-19.pdt

17 Centers for Disease Control and Prevention. Evaluating and testing persons for coronavirus disease 2019 (COVID-19). 2020 https://www.cdc.gov/coronavirus/2019-ncov/hcp/clinicalcriteria.html

18 An antibody test for the novel coronavirus will soon be available. Economist 2020 Apr 2. https://www.economist.com/science-and-technology/2020/04/02/an-antibody-test-for-thenovel-coronavirus-will-soon-be-available

19 Department of Health and Social Care. Coronavirus (COVID-19): scaling up our testing programmes, 4 Apr 2020. https://www.gov.uk/government/publications/coronavirus-covid19-scaling-up-testing-programmes

Published by the BMJ Publishing Group Limited. For permission to use (where not already granted under a licence) please go to http://group.bmj.com/group/rights-licensing/ permissions 